\title{
Australia sets priorities for future research
}

Carina Dennis, Sydney

All Australian government research agencies should be working towards environmental sustainability, promoting and maintaining health, developing new technologies and safeguarding the nation, according to a long-awaited list of priorities published by the government on 5 December.

Researchers have broadly welcomed the priority list — and the freedom that the government says it will allow agencies in sticking to it. "I'm pleased with the outcome - it will help to focus the mind but retain some flexibility," says Kenneth Baldwin, a laser physicist at the Australian National University in Canberra, and chair of the policy committee of the Federation of Australian Scientific and Technological Societies.

Some had feared that the conservative government of Prime Minister John Howard would issue a far more prescriptive list of what Australian researchers should be doing. But agencies are expected to make marked changes to align their programmes with the new priorities - and may get more direct marching orders from the government if they don't.

The exercise "sets a broad picture, and leaves a level of flexibility underneath", says Vicki Sara, chief executive of the Australian Research Council (ARC), the nation's main grant agency for non-biomedical research.

Some agencies have already initiated steps to redirect their programmes in anticipation of the government's announcement. Earlier this year the Commonwealth Scientific and Industrial Research Organisation (CSIRO), which runs a network of public laboratories, said that it will redirect $30-40 \%$ of its budget into seven "flagship" programmes by 2006 .

The community's broadly positive response to the announcement was in marked contrast to the uproar over the ARC prioritization, announced in January, which was criticized for lack of consultation and for being announced too close to grant application deadlines (see Nature 415, 724;2002).

"Presumably, lessons were learned from that experience and consultation has been wider this time," says Baldwin. For the December announcement, the government took advice from a panel of scientists and business leaders, held public discussions around the country, and read over 180 written submissions.

Australia's research agencies are expected to outline plans to implement the new priorities within six months. "We will need to articulate our efforts if we're to maintain a light-touch partnership with the government - if not, we could expect a more explicit directive," says plant geneticist Jim Peacock, president of the Australian Acade- my of Science and chair of the government's advisory committee for priority setting.

The prioritization won't be accompanied by any extra money, admits government chief scientist Robin Batterham. Nevertheless, he hopes it will help foster more research collaborations, and that these will be further encouraged by an audit of publicly funded research which the government plans to conduct in 2003.

"We expect to see new collaborations arising from this, as researchers identify common problems and goals", says Peacock.

"There is a culture of independence across the agencies that needs to be overcome," adds Graham Harris, an ecologist and chair of the CSIRO's flagship programmes. Addressing that may prove tougher than it sounds, according to Sara: "There is a problem with fragmentation in Australian research," she says, "and the challenge will be pulling people together."

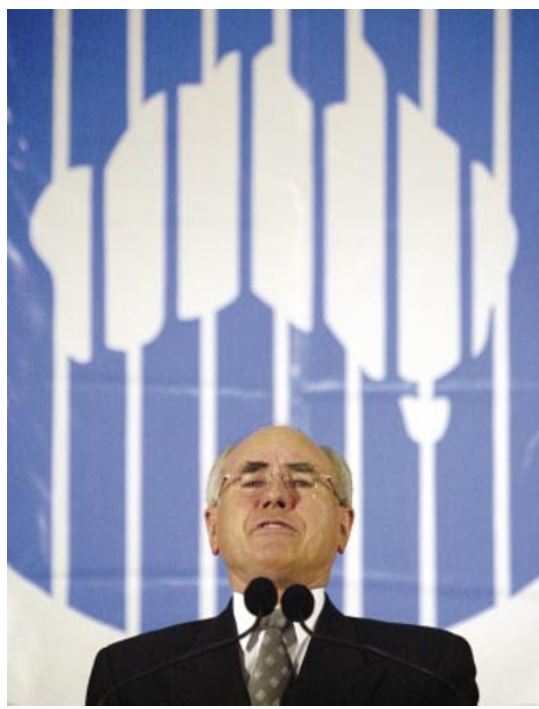

John Howard's government will allow agencies to be flexible in following research guidelines.

\section{Ousted creationist sues over website}

\section{Geoff Brumfiel, Washington}

A Tennessee creationist is suing the operators of a popular physics website that refused to publish his alternative Big Bang hypothesis.

Robert Gentry, a lifelong Seventh-Day Adventist, filed the suit in the district court at Knoxville, Tennessee, against the operators of the arXiv preprint server, claiming that they refused a series of ten of his papers because of their religious content. Counsel representing the chief defendant, Cornell University in Ithaca, New York, says the claims have no merit and that the university has the right to choose what appears on the site.

Gentry, who has a masters degree in physics from the University of Florida, had papers in nuclear geophysics published in journals, including Science and Nature,

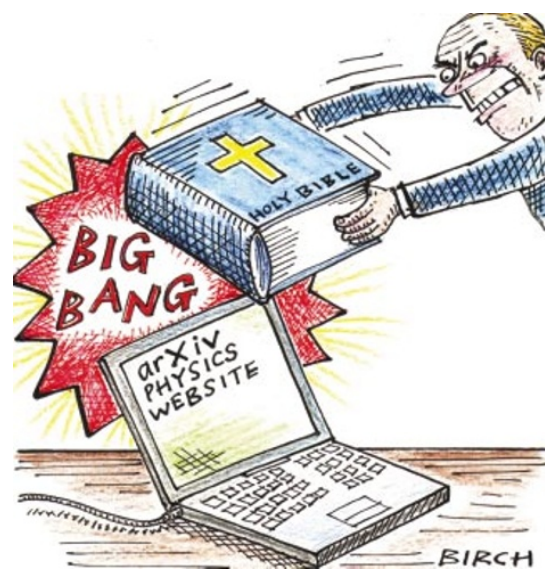

during the 1960s and 1970s. Those papers, he says, inspired him to come up with an alternative Big Bang hypothesis, which he submitted unsuccessfully to academic journals. He then tried posting his articles on the arXiv preprint server - a non-peerreviewed website where physicists often post papers before submitting them to journals. When arXiv curators removed the papers and revoked his posting rights in 2001, Gentry complained, then filed the suit to regain access this August. "I'm a creationist and a believer in the Bible, but I want to know the truth. I want these papers to be tested by the scientific community," he says.

Paul Ginsparg, a professor at Cornell and creator of the site, declined to comment, citing the ongoing suit. But Nelson Roth, Cornell's associate counsel in charge of litigation, says that the rejection was based on Gentry's lack of academic affiliation, not his beliefs. "The religious views of the plaintiff are completely irrelevant," he says.

Even if the legal case makes no progress, it highlights some problems associated with websites whose content is not peer-reviewed, says Adrian Melott, a cosmologist at the University of Kansas in Lawrence. Melott, a co-founder of Kansas Citizens for Science, a group that has successfully lobbied against teaching creationism in the state's schools, says he's noticed a rise in "flaky" publications on the section of the arXiv server that he uses most. "We're coming to a crunch" over what can be published on open servers, he says. 